\title{
PRODUCT FEATURE AS A DETERMINANT OF THE INDUSTRIAL BUYING METHOD
}

\author{
Anna CELIŃSKA \\ FCA Group Purchasing Poland Sp. z o.o.; anna.swierczek@interia.pl, ORCID: 0000-0001-9137-1090
}

Purpose: The purpose is to present how a product feature, as determinant, affects selection of the appropriate buying method. The correct buying method choice provides companies with many advantages in terms of cost savings achieved within the organisation.

Design/methodology/approach: The main method used is case study. The measurement of the result is based on target achievement set by a company. In addition the article reveals a new mathematical analysis of learning curve using integral calculation.

Findings: Two determinants are presented - vulnerability to engineering changes and high labour intensity. Analyses show that choosing adequate buying method to a certain purchasing situation influences cost performance. There is also deliberation of new mathematical analysis of learning curve as supportive tool for industrial buyer.

Research limitations/implications: The main limitation of this research is impossibility to test effectiveness of using different buying methods scenarios under the same conditions.

Practical implications: For practitioners, buying method should be carefully chosen in relation to certain purchasing situation, e.g. product feature should be considered as one of the determinants. The article also provides supportive tool for price negotiations using learning curve phenomenon.

Originality/value: The article presents how two determinants, frequent engineering changes and high labour intensity, affecting optimal industrial buying method selection in order to achieve better cost performance. In addition the article revealed new mathematical analysis of learning curve as supportive tool for professional buyers to be used during direct negotiations with suppliers.

Keywords: learning curve, experience curve, direct labour costs, bestshoring, buying method.

Category of the paper: case study.

\section{Introduction}

Purchasing departments are under increasing pressure exerted by the management of their companies to reduce costs by obtaining savings from suppliers. As a result of this, they often resort to the simplest and fastest methods of looking for savings, not paying due attention to the 
proper choice of the methods. Such actions often result in a failure to achieve the set cost targets or in the achievement of targets only in terms of purchasing costs, with additional costs generated in other areas of the organisation (e.g. logistics, quality control department or administration).

Moreover, the activity of purchasing departments is increasingly exposed to unexpected changes related to the risk of reduced access to resources, raw material shortages, political turmoil, governmental interventions on the markets, intensified competition or accelerating technological changes (Kraljic, 1983).

These changes force purchasing departments to implement advanced technologies and to make more risky decisions. The fundamental question which every manager has to face is: where should my supply sources be located in the world so that the goals and strategies of the organisation can be achieved in the best way? The unpredictable and fast-changing environment forces purchasing departments to constantly re-evaluate the impact of their purchasing strategies on the revenue (mark-up) of the company through TCO - Total Cost of Ownership (Monczka et al., 2016).

The product feature is one of the determinants which significantly affect the selection of the suitable purchasing method. Considering the issue in this aspect, the decision maker will choose a different purchasing method when purchasing several thousand tonnes of raw material and a different one when purchasing a single service. This article focuses on two features vulnerability to engineering changes and the degree of labour intensity in the production of a given product.

\section{Bestshoring}

Literature mentions a number of variables which influence the purchasing process. These variables include inter alia, product features, strategically important product, purchase volume expressed in money, market structure form, degree of risk related to the purchase, influence of the purchasing department on the purchasing process or the degree in which the purchased product affects the routine of organisation (Weele, 2017). Currently the term bestshoring is poorly defined in academic publication. One of the sources defines the term as a "way the supplier locates its resources where they are best deployed according to the notion of fair quality for a fair price" (Oshri et al., 2009). Also bestshoring is defined as "a comprehensive evaluation of which region or country is the most suitable match for producing a certain item or service" (Schuh et al., 2017). Hillary Clinton in 2004 published an article in Wall Street Journal explaining why choosing bestshoring instead of outsourcing can be much more cheaper (Clinton, 2004). According to Wikipedia, bestshoring is known as rightshoring, "the process of 
identifying the best location to move manufacturing, IT or business processes for a company" (Wikipedia).

Purchasing departments are under constant pressure to achieve better results in areas such as cost reduction, searching for innovative solutions or improving suppliers' quality results. As a consequence, after access to the Eastern European, Chinese or Indian markets opened and over billion additional, very cheap workers became available, companies started to make use of this potential and to locate their suppliers in these markets in order to obtain primarily cost benefits, expecting, at the same time, that the suppliers located in the so-called low cost markets (LCC - Low-Cost Country - mainly the regions of Asia-Pacific, Latin America, Eastern Europe) would develop their skills in order to meet the high standards imposed by the companies based in the highly developed countries.

Searching for suppliers on the worldwide market (offshoring) undoubtedly brings many advantages, especially including: low labour cost, access to the only existing source of supplies, e.g. rare minerals obtained mainly in China (in April 2010, China extracted 97.3\% of the global production) (Manchieri and Chandrasher, 2016), access to new markets, innovation, possibility of getting to better know the preferences of local customers or stimulating competitiveness on the local market by inviting suppliers from all over the world to tenders in order to change the bargaining position. Lower costs can also be obtained thanks to countries which have less rigorous environmental regulations. This phenomenon was used, e.g., by companies operating in the EU cement industry. When the energy costs in the EU increased due to, inter alia, the $\mathrm{CO} 2$ emissions trading system and mandatory $\mathrm{CO} 2$ emission reductions in the industry, companies decided to outsource the production of clinker to China (Official Journal Of European Union).

As companies searching for benefits on the global scale gained more experience with the passage of time, some evident problems emerged concerning, among other things, lack of qualified personnel or the impossibility to meet high qualitative and environmental requirements (mainly in the countries defined as LCC). Companies also had to cope with considerable difficulties related to the process and risk management. The first area concerned logistic complexity which consists in long lead times (in this case, it is the period between order placement and its delivery to the customer) caused by the need to transport the goods over very long distances by sea, railway and road. This situation resulted in the increase of, inter alia, stock maintenance and stock insurance costs. Additionally, companies had to send orders (logistic programmes) to suppliers, e.g., located in China 6-12 weeks in advance. Otherwise, the components would not have been delivered on time, i.e. at the moment when they were required by the production plant. Freezing the orders so far in advance caused a complete lack of flexibility, e.g. during the modifications of production plans or implementation of engineering changes. 
In the dynamically changing global economy, the tender process on a global scale (globalisation) has also changed significantly, especially its motives. In the seventies of the twentieth century, the need to search for supply sources on a global scale was due to various shortages, and the main reason for adopting this method was the low cost/prices which could be negotiated in these regions and in the low-cost countries (LCC). However, over time, this approach began to change, moving towards TCO (Total Cost of Ownership). The following factors began to be analysed: the costs of stock maintenance, the costs of a complicated supply chain exposed to many risks on such long distances, the costs of very low-quality components produced in the low-cost countries and, finally, the dissatisfaction of the final customer who complained about the long lead time and lack of flexibility, e.g. in the changes of programmes. Many years ago, the vice president responsible for global tenders in Honeywell Process Solutions said, "If we cannot send ordered products because our supplier doesn't respond in a sufficiently quick time or if we lose a business customer due to our long lead time, then the low costs do not help us in any way." (Monczka et al., 2016, p. 366). In the end, the choice of the purchasing method on a global scale is justified on the basis of the revenue/mark-up of the company, and not only low costs.

For some time, however, an opposite trend has been observed. Many companies have decided to relocate their plants and return to Europe in order, as they say, to be closer to their customer. An example of this trend is a company producing filters and heat exchanges for the automotive industry, Ufi Filters Poland sp. z o.o. This company, in July 2017 (Financial Statement of Ufi Filter Poland Sp. z o.o.), received permission to operate in the Special Economic Zone of Wałbrzych. Although the company already has six plants in China, the management decided to open the first plant in Poland. The president of Ufi Filters explained this strategic decision in the following way: “(...) we are trying to serve our customers even more effectively on the local level. Thanks to the opening of this key plant in Poland, we can satisfy the demands of all the main car producers in Europe and reduce the delivery time." (Hanszke, 2018).

The above examples show that the time factor, understood as quick access to raw materials, subcomponents, services and the short reaction time of the supplier to production plan changes, begins to play an increasingly important role, even compared to the cost aspects.

\section{Learning curve}

Learning curve is an empirical phenomenon which consists in a decrease of the labour costs by a certain percentage with the increasing (accumulated) and continued production of a given product. Learning curve and experience curve are often used interchangeably, even though in the narrower sense they should be distinguished. Learning curve refers only to the decrease in 
labour cost, whereas the experience curve has a wider range and refers to the Total Life of the Product. This means that the curves differ from each other mainly in terms of the production range, in which cost reductions are expected, and the reasons for the cost reductions (Hall and Howell, 1985). Cost reductions most often are the result of:

- more efficient line feeding,

- line operating speed,

- improved operator familiarity with the tools,

- technological development (Newman, 1992, p. 104).

Cost reductions resulting from the learning curve occur in a regular (predictable) way and depend on the cumulative production volumes. The learning curve should help companies not only in the cost prediction, but also in reducing the costs in a more dynamic way. Companies which learn faster are more likely to become successful (Zangwill and Kantor, 2000). However, the learning curve does not continue forever. After a certain level of production volumes is reached, the cost reductions become so low that, in practice, they are insignificant.

William J. Abernathy and Kenneth Wayne define the learning curve as a concept which assumes that the product costs systematically decrease by a certain percentage whenever the production doubles. They also point out a practical example of the average price reduction of the model T Ford, which, between 1909 and 1923, was reduced from $\$ 5,000$ to $\$ 900$, presenting the learning curve with a slope of $85 \%$, and in the initial production period of less than two years, it was reduced from $\$ 5,000$ to $\$ 3,000$ (Abernathy and Wayne, 1974).

The range of the learning curve increases with the increase of manual labour share. The table below presents the learning curve ranges linked to the manual and automated labour distribution, expressed in percentages and developed by Richard Newman. As can be seen in the table, the larger the manual labour share, the greater the effect of the learning curve and, as a consequence, the bigger the cost reductions.

Table 1.

Learning curve ranges

\begin{tabular}{|l|l|}
\hline Process & Learning curve range \\
\hline Highly automated assembly & $98-99 \%$ \\
\hline $25 \%$ manual labour, $75 \%$ automated labour & $95-97 \%$ \\
\hline $50 \%$ manual labour, $50 \%$ automated labour & $90-95 \%$ \\
\hline $75 \%$ manual labour, $25 \%$ automated labour & $85-89 \%$ \\
\hline $100 \%$ manual labour, $0 \%$ automated labour & $75-84 \%$ \\
\hline
\end{tabular}

Adapted from: "Supplier price analysis: a guide for purchasing, accounting and financial analysts" by R. Newman, 1992, New York: Quorum Books, p. 106.

The learning curve allows companies to find cost reduction sources by reducing the quantities of waste, eliminating some superfluous activities in the process (shortening production cycles), eliminating duplicate activities, identifying gaps in training, adjusting machines in a better way, changing software etc. One of the problems of the learning curve is statistical issues and the problems with calculating the effect of these improvements or upgrades 
in terms of cost reduction. These issues are very important for the management in order to make the right decisions.

One product or process can be more susceptible to cost reduction than another, e.g. the costs related to the production process have an experience curve with a steeper slope than marketing, sales or distribution costs. Moreover, a particularly steep slope is typical for the products which have the following features: standardisation, complexity and labour intensity.

Soft skills, such as vision and leadership, are of enormous significance in the process of obtaining cost reductions that have roots in the learning curve. A deep conviction that progress is possible, creating conditions that foster continuous improvement, support given to employees in their efforts, flexibility and openness to change stimulate and have a positive impact on the effects of the learning curve (Hirschmann, 1964).

\section{Case study 1 - vulnerability of the purchased product to engineering changes}

A company operating in the automotive industry in Poland launched a new product in 2008 and had to sign a multi-year contract for the supply of electric components. The purchasing department conducted a tender about a year and a half before the planned SOP - Start of Production. As a result of the tender and several rounds of negotiation, the decision was made to diversify the supplies, and a contract was signed with two suppliers (dual sourcing), each of them being assigned with $50 \%$ of the annual production volume. One supplier was located in Poland (approx. $30 \mathrm{~km}$ from the final delivery destination), the second one, much cheaper, in Morocco (over 3,500 km from the final destination of delivery by sea and land). The choice of such a method (dual sourcing) was dictated by both economic and security issues (securing delivery continuity in case of any problems with one of the suppliers). In both cases, the incoterms were established as FCA (Free Carrier) - customer's plant. The components purchased from Morocco in 2008 at an exchange rate of 3.3668 were cheaper by $19 \%$ (Table 2) in comparison with the Polish (local) supplier. The main cost driver with the component in question was labour, as the production process required manual labour.

Table 2.

Calculation of the impact of change of exchange rate on the price in September 2008 exchange rate 3.3668

\begin{tabular}{|c|c|c|c|c|}
\hline $\begin{array}{c}\text { Supplier A - price } \\
\text { [PLN] }\end{array}$ & $\begin{array}{c}\text { Supplier B - price } \\
\text { [EUR] }\end{array}$ & $\begin{array}{c}\text { Supplier B - price } \\
\text { [PLN] }\end{array}$ & $\begin{array}{c}\text { Delta price } \\
\text { between supplier } \\
\text { A \& B [PLN] }\end{array}$ & $\begin{array}{c}\text { Saving between } \\
\text { supplier A \& B } \\
{[\%]}\end{array}$ \\
\hline 280 & 67 & 225.6 & -54.4 & $-19 \%$ \\
\hline
\end{tabular}

Source: own elabouration based on the exchange rate of the Polish National Bank (NBP) https://www.nbp.pl/transfer.aspx?c=/ascx/ListABCH.ascx\&Typ=a\&p=rok;mies\&navid=archa. 
It was known that the prices of the components purchased in Morocco were exposed to currency risk, but the difference in the price, amounting to almost $20 \%$, was so attractive and significant that it was assumed that this was a safe level. In 2016, when the Polish zloty weakened against the euro, the whole assumed savings deriving from the purchase from the supplier located in Morocco was cancelled due to the unfavourable exchange rate. In 2016, with an exchange rate of 4.325, the piece per price of the component delivered from Morocco was higher by $3 \%$ compared to the price of the Polish supplier (Table 3 ). Moreover, the distant location also had a largely negative impact on logistic processes.

Table 3.

Calculation of the impact of change of exchange rate on the price in September 2016 exchange rate 4.325

\begin{tabular}{|c|c|c|c|c|}
\hline $\begin{array}{c}\text { Supplier A - price } \\
\text { [PLN] }\end{array}$ & $\begin{array}{c}\text { Supplier B - price } \\
\text { [EUR] }\end{array}$ & $\begin{array}{c}\text { Supplier B - price } \\
\text { [PLN] }\end{array}$ & $\begin{array}{c}\text { Delta price } \\
\text { between supplier } \\
\text { A \& B [PLN] }\end{array}$ & $\begin{array}{c}\text { Saving between } \\
\text { supplier A \& B } \\
\text { [\%] }\end{array}$ \\
\hline 280 & 67 & 289.8 & 9.8 & $3 \%$ \\
\hline
\end{tabular}

Source: own elaboration based on the exchange rate of the Polish National Bank (NBP) https://www.nbp.pl/transfer.aspx?c=/ascx/ListABCH.ascx\&Typ=a\&p=rok;mies\&navid=archa.

The first factor was the long lead time. In the case of the supplier located in Morocco, the planned production volumes had to be "frozen" for six weeks, and in some cases even eight weeks in advance. This meant that if, for various reasons, the customer changed the planned volumes, e.g. to smaller quantities than those included in the forecast, he had to accept the forecast quantities anyway and pay for them, because the supplier had already produced them. This kind of problem also occurred in the opposite scenario. If the customer needed to increase the demand in a short time, he couldn't do this either, because, similarly, he had a lead time of six weeks. In most cases, the long lead time, and the resultant low flexibility, is a factor which most companies can manage, because it is planned for and is not an element of surprise. In this case the problem consisted in the fact that the purchased component was subject to very frequent engineering changes. The component in question was frequently modified for technical reasons, as any change in the final product automatically required more or less significant modifications of this component. This characteristic of the product generated a considerable quantity of obsolete materials throughout the year, which had to undergo a costly scrapping process. The costs were generated mainly when the company, e.g. for quality reasons, had to implement a change quickly, even though the supplier had already produced the unmodified components. These components were no longer fit for use, e.g. for quality or safety reasons, but they had to be accepted and paid for. The idea to recycle some elements or raw materials from the obsolete components turned out to be much more expensive than any possible benefits from recycling. After project closure, the company calculated that the final costs of the obsolete materials amounted to several thousand euro. 
As a result of the lesson learned, the company recognised that in the case of suppliers for components with a high frequency of technical modifications, the supplier location is an essential factor to be considered when making a decision. In such cases, closer locations should be considered in order to minimise obsolete material costs. If the supplier independently decides to change the location after he has already been nominated for business and before production launch (e.g. if, in the meantime, he was forced to relocate in order to optimise the production capacity), all the costs related to obsolete materials should be charged directly to the vendor, not the purchaser. Another issue concerns the exchange rate exposure, which must be included in the calculation of the scenarios for supplier selection and currency hedging must be considered, which should also be included in the calculations.

An important lesson learned from the presented case study is that when choosing the optimal purchasing method, it is necessary to consider such factors as specificity of the purchased product, geographical location and exchange rate exposure. In this case, choosing a method such as searching for suppliers in a distant location (offshoring) or in low-cost countries (LCC) would be less beneficial than, e.g., choosing a supplier from less distant regions in terms of geography, culture, organisation or legal aspects (nearshoring).

\section{Using mathematical analysis of the learning curve as a negotiation argument in the case of labour-intensive components}

The priority of the purchasing departments is to constantly search for cost reductions. Therefore purchasing departments, before they reach for external supply sources and more time-consuming purchasing methods, should firstly decide to adopt less risky and faster methods (e.g. negotiating price reductions with their current suppliers). In order to make sure that direct negotiations with the supplier are successful, it is necessary to thoroughly prepare for them and to develop arguments that are difficult to undermine. If the buyer is dealing with the purchase of a labour-intensive product (e.g. where the direct labour cost represents $25 \%$ or more of the given component price), he can base his negotiation line on a mathematical analysis of the learning curve and, more specifically, determine the average labour cost taking into consideration the learning curve effect. To calculate this cost, it is necessary for the supplier to define the learning curve, which is specific for each company.

The mathematical analysis of the learning curve presented below is my own elaboration, based on the sample data from the book by R.G. Newman "Supplier Price Analysis. A guide for purchasing, accounting and financial analysts" (Newman, 1992, p. 105). 
Data for the analysis provided by the supplier:

- Learning curve [\%]: 95\%, starting with the first 100 pieces produced.

- Direct labour cost without considering the learning curve effect: $\$ 50$ (we apply this amount for the hundredth piece produced).

- Contract quantity: 20,000 pieces.

The average cost of direct labour, considering the learning curve effect, must be calculated as shown below:

Stage 1 - determine the labour cost for producing the first piece

Firstly, it is necessary to calculate the labour cost of the first piece according to the formula $\mathrm{a}=\mathrm{Y} / \mathrm{x}^{\wedge} \mathrm{b}$, where " $\mathrm{a}$ " means labour cost for producing the first piece, "Y" is the labour cost for $\mathrm{x}$ piece, " $\mathrm{x}$ " is the number of produced pieces, and " $b$ " is Log(Learning curve $) / \log 2$.

$$
\begin{aligned}
& a=\frac{Y}{x^{b}} \\
& b=\frac{\log (\text { LearningCurve })}{\log 2}=\frac{\log (0.95)}{\log 2}=-0.074 \\
& a=\frac{50}{100^{b}}=\frac{50}{100^{-0.074}}=\frac{50}{0.71}=\$ 70.3
\end{aligned}
$$

Direct labour cost of producing the first piece is $\$ 70.3$.

Stage 2 - determine the direct labour cost of the twenty thousandth piece (contract quantity), according to the following formula:

$$
Y=a x^{b}=70.3 * 20000^{-0.074}=\$ 33.78
$$

The direct labour cost of producing the twenty thousandth piece is $\$ 33.78$. For negotiation purposes, we can show to the supplier that at the end of the contracted project, the unit cost of direct labour will amount to $\$ 33.78$, i.e. it will decrease by over $50 \%$ in comparison with the cost of the first piece $(\$ 70.3)$.

Stage 3 - define the average labour cost taking into consideration the learning curve effect

Due to the fact that it is technically impossible to establish individual prices for every produced piece (the first, the hundredth, the twenty thousandth, etc.), it is necessary to calculate the average cost of the direct labour required to produce the whole ordered batch, i.e. 20,000 pieces and include it in the price. The matter wouldn't be complicated mathematically if this cost was fixed or if it decreased in a linear way. However, in our case, the cost decreases in a non-linear way; therefore a differential calculation must be used. The total cost of direct labour required to produce a certain number of pieces constitutes the value of the field under the function graph of the relation between the unit cost and the production volume. Since the cost of producing the zero piece does not exist, we begin the analysis from the first piece, omitting the zero piece. The field under the graph constitutes the value of the definite integral from the above function (Figure 1). In our function of the learning curve: 


$$
Y=a x^{b}
$$

we will use the formula for the calculus:

$$
\int x^{n} d x=\frac{x^{n+1}}{n+1}+C
$$

In our case, the total cost (TC) of producing 20,000 pieces will be (with a slight simplification of omitting one piece to exclude the zero piece):

$$
\begin{aligned}
T C & =\int_{1}^{20001} a x^{b} d x \\
T C & =a * \frac{20001^{b+1}}{b+1}-a * \frac{1^{b+1}}{b+1}=70.3 *\left(\frac{20001^{-0.074+1}}{-0.074+1}-\frac{1^{-0.074+1}}{-0.074+1}\right) \\
T C & =70.3 *\left(\frac{20001^{0.926}-1^{0.926}}{0.926}\right)=70.3 *\left(\frac{9611.12-1}{0.926}\right)=\$ 729.571,27
\end{aligned}
$$

After taking into consideration the learning curve, the total cost of producing 20,000 pieces is $\$ 729,517.27$, thus the average cost of producing one piece is $729,571.27 / 20,000=\$ 36.48$.

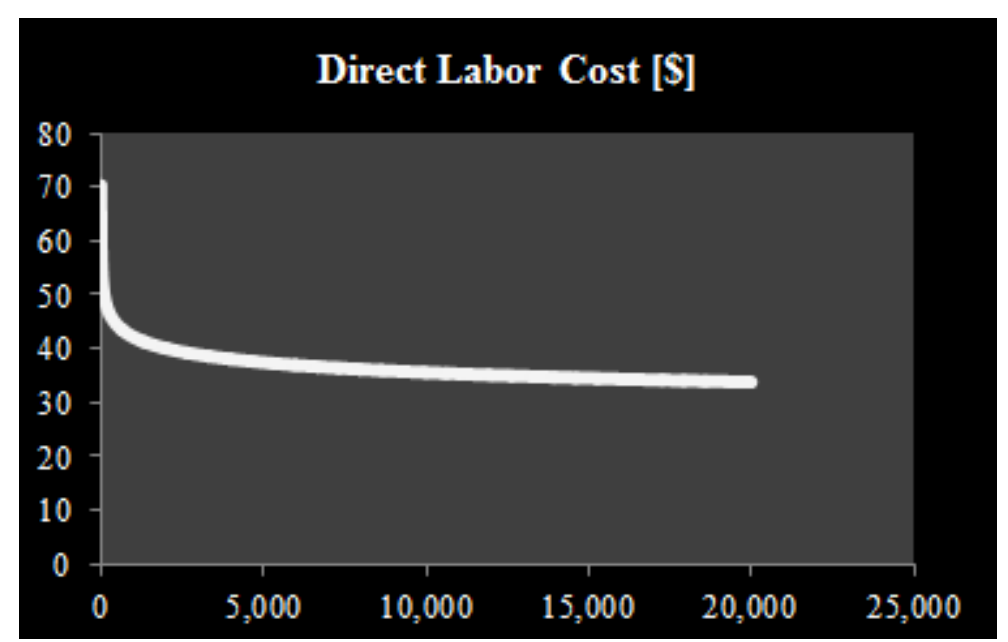

Figure 1. Evolution of the direct labour cost, taking into account the learning effect. Source: own elaboration.

During price negotiations with supplier, it is necessary to present and explain the calculations and then demand a reduction of the labour cost from $\$ 50$ to $\$ 36.48$ for an order of 20,000 pieces. The main counter-arguments of the supplier are the following: high employee turnover, frequent engineering changes, production in a smaller series resumed at intervals (decline in habits) or production relocation (new building, new geographical location). The supplier must submit to the other party well-documented data confirming the decline of the learning effect, which should be analysed individually. 


\section{Discussion, limitation and implication}

The present study assumes that adequate buying method selection, in opposition to choosing routinely the easiest method without deeper reflection, influences achievement of bigger cost reduction. This hypothesis is supported by described case studies. The study analyses different determinants, which have an impact on choosing industrial buying method. It concentrates on finding out more determinants and especially critical one, which have the most significant influence on cost performance and therefore should be carefully analysed and taken into account by the buyers. The future challenge of this research is to elaborate a tool/guideline, which would support and motivate buyers at operating level to search for optimal choice of buying method. Although the tool would be very supportive, the proper buying method selection requires experience (experiential learning), purchasing knowledge and motivation of each professional buyer.

According to my best knowledge, literature focuses rather on supplier selection technique, than on buying method selection, so there is a gap in this area. In 2008 the "Purchasing chessboard" - the procurement strategy tool based on supply power and demand power logic, was published by A.T. Kearney. It contains reservoir of methods and can be very useful tool for buyer in finding adequate buying method. The weakness of this tool is subjective positioning of buyer and seller power on the chessboard and it does not contain all purchasing methods. The research concentrates on closing the gap in this area.

The main limitation of this research is impossibility to test effectiveness of using different buying methods scenarios under the same conditions, like, e.g. testing what is more effective in a specific purchasing situation - reverse auction or direct negotiation. As a consequence the research is based on different case studies and results are measured in regard to a set target (success achievement) and in some cases supplier feedback/reaction. Another limitation is that purchasing situations are inhomogeneous, so it is difficult to categorize them in simple way. Anyway, analysing case by case, it can be recognized that negative consequences of using specific buying methods are recurring, so this phenomenon can be used to elaborate guidelines for buyers.

For management, this research has emphasized the importance of considering different determinants while choosing buying method. This approach can significantly improve cost performance of the companies and in some cases improve relationship with suppliers. One of the biggest challenges ahead of management is the question how to motivate the buyers, so they are inspired to search for the best match buying method to certain purchasing situation, instead of choosing routinely easiest way to source. In addition, it is essential that buyers should have an adequate purchasing knowledge (quite rare within the corporation), so that they are familiar with a wide range of buying methods and know how to apply them. Nowadays, purchasing training market offers a lot of courses related to soft skills like negotiations, 
but there is a lack of specialized and econometric training for buyers. Also purchasing classes are rarely available at universities.

\section{Conclusion}

Professional buyers are under constant pressure concerning time and cost. Therefore they routinely choose the fastest and simplest purchasing methods, not paying particular attention to an analysis of, e.g., product characteristics. The cases described in the article draw attention to the necessity of selecting purchasing methods tailored to, e.g., product features (individualised methods). The author focused on two product features as determinants for choosing the purchasing method - product vulnerability to engineering changes and high labour intensity. It was demonstrated that the production location for a component characterised by a high frequency of engineering changes should be relatively close to the final production plant. This approach will allow, inter alia, one to avoid obsolete material costs and increase the flexibility of supplies. On the other hand, during direct negotiations with suppliers concerning the prices of components with a high manual labour share, the learning curve can be used to obtain cost reductions.

In conclusion, it should be noted that purchasing departments, before beginning the purchasing process, should look more closely at the object of purchase in order to choose the most suitable method (individual approach).

\section{References}

1. Abernathy, W.J., Wayne, K. (1974). Limits of the learning curve. Harvard Business Review. Retrieved from https://hbr.org/1974/09/limits-of-the-learning-curve, 9.10.2019.

2. Bestshoring (2017, March 5). In Wikipedia. https://en.wikipedia.org/wiki/Bestshoring.

3. Clinton, H. (2004). Bestshoring beats outsourcing. Wall Street Journal. Retrieved from https://www.wsj.com/articles/SB109079435782473263, 19.04.2020.

4. Dachs, B., Kinkel, S., Jager, A., Palcic, I. (2019). Backshoring of production activities in European manufacturing. Journal of Purchasing and Supply Management, Vol. 25, Iss. 3. Retrieved from https://www.sciencedirect.com/science/article/abs/pii/S14784092183 00372, 20.01.2020.

5. Hall, G., Howell, S. (1985). The experience curve form the economist's perspective. Strategic Management Journal, Vol. 6. 
6. Hanszke, E. (2018). Włoski Ufi Filters uruchomit fabryke w Opolu. Zatrudni w niej 250 pracowników. Polska Times. Retrieved from https://polskatimes.pl/wloski-ufi-filtersuruchomil-fabryke-w-opolu-zatrudni-w-niej-250-pracownikow/ar/13742164, 6.02.2019.

7. Hirschmann, W.B. (1964). Profit form learning curve. Harvard Business Review. Retrieved from https://hbr.org/1964/01/profit-from-the-learning-curve, 11.09.2017.

8. Kraljic, P. (1983). Purchasing must become supply management. Harvard Business Review. Retrieved from https://hbr.org/1983/09/purchasing-must-become-supply-management, 25.02.2018.

9. Lacity, M.C., Khan, S.A., Willcocks, L.P. (2009). A review of the IT outsourcing literature: Insights for practice. Journal of Strategic Information Systems, 18, 130-146. Retrieved from https://www.sciencedirect.com/science/article/abs/pii/S0963868709000195.

10. Mancheri, N., Chandrasher, S. (2013). Dominating the World China and the Rare Earth Industry. National Institute of Advanced Studies. Retrieved from https://www.researchgate.net/publication/313477894_Dominating_the_World_China_and _the_Rare_Earth_Industry, 11.12.2019.

11. Monczka, R., Handfield, R., Giunipiero, L., Patterson, J. (2016). Purchasing and supply management. Boston: Cengage Learning.

12. Newman, R. (1992). Supplier price analysis: a guide for purchasing, accounting and financial analysts. New York: Quorum Books.

13. Official Journal Of European Union 2008/C 10/17 https://eurlex.europa.eu/LexUriServ/ LexUriServ.do?uri=OJ:C:2008:010:0059:0066:PL:PDF.

14. Oshri, I., Kotlarsky, J., Willcocks, L.P. (2009). The handbook of global outsourcing and offshoring. Palgrave Macmillan.

15. Schuh, Ch., Raudabaugh, J., Kromoser, R., Strohmer, F., Triplat, A., Pearce, J. (2017). The purchasing chassboard. 64 methods to reduce costs and increase value with suppliers. Berlin: Springer, 22.

16. Weele, A.J. (2017). Purchasing \& Supply Chain Management. Andover: Cengage Learning EMEA.

17. Zangwill, W., Kantor, P. (2000). The learning curve: a new perspective. International Transaction in Operational Research, Vol. 7, Iss. 6, 595-607. 